
\title{
28 Research Square \\ Wildfire Smoke Exposure Is Associated With Severe Pulmonary Exacerbation in Adult Cystic Fibrosis Patients
}

\section{Lily Amanda Cook ( $\square$ cooli@ohsu.edu )}

Oregon Health \& Science University https://orcid.org/0000-0002-2949-4978

\section{Bethany Collins}

Oregon Health \& Science University

Aaron Trimble

Oregon Health \& Science University

\section{Research Article}

Keywords: Cystic fibrosis, pulmonary exacerbation, wildfire smoke, environmental factors, western United States

Posted Date: June 10th, 2021

DOl: https://doi.org/10.21203/rs.3.rs-589345/v1

License: (c) (i) This work is licensed under a Creative Commons Attribution 4.0 International License. Read Full License 


\section{Abstract}

\section{Purpose}

Because pulmonary exacerbations in cystic fibrosis cause a step-wise decline in FEV1 function and contribute significantly to disease progression, it is important to identify potential environmental triggers. Studies have been done on general air quality and its relationship to cystic fibrosis disease activity, but none have examined air pollution caused by wildfire smoke. Our study intends to better understand this relationship.

Methods

A retrospective cohort study was conducted using data collected from people with cystic fibrosis (CF) between 2012 and 2019. Data on pulmonary exacerbations was extracted from the patient registry hosted and maintained by the Cystic Fibrosis Foundation. Exposures were determined using measurements of fine particulate matter $\left(\mathrm{PM}_{2.5}\right)$ from the Environmental Protection Agency. A logistic regression model was created in order to identify both univariate and adjusted odds ratios and their associated confidence intervals.

Results

82.7\% $(n=415)$ of individuals with CF experienced an exposure to wildfire smoke during the study period. The adjusted odds ratio for a pulmonary exacerbation within one month following an exposure to wildfire smoke was $1.50(95 \% \mathrm{Cl}=1.13-1.99, \mathrm{p}=0.006)$ for adults and $0.92(95 \% \mathrm{Cl}=0.69-1.23, \mathrm{p}=0.578)$ for children.

\section{Conclusion}

Wildfire smoke exposure is associated with severe pulmonary exacerbation in adults but not in children. This suggests that wildfire smoke may be an environmental risk factor for exacerbation in adults with CF. Further study is needed to understand why and how wildfire smoke exposure affects adult with CF differently than the pediatric population.

\section{Introduction}

In people with cystic fibrosis, pulmonary exacerbations are associated with a decreased quality of life, increased morbidity and mortality, and stepwise disease progression [1]. For these reasons, it is important to better understand the mechanisms driving exacerbations as well as to identify potential triggers. Another motivation for this work is that people with CF have identified environmental effects on disease course as a research priority. In a recent survey of 1900 members of the CF patient community, geographic and environmental factors influencing respiratory health was selected as one of the top-three funding priorities [2]. 
Overall poor air quality has been shown to be associated with pulmonary exacerbations in cystic fibrosis patients [3-5], but the relationship between air pollution caused by wildfire smoke and CF exacerbations has not been investigated. Wildfires are a unique cause of pollution affecting both urban and rural areas, and can cause extremely poor air quality over a relatively short period of time in a region that otherwise enjoys good air quality. Some evidence from the general population has suggested that smoke from wildfire may have different health effects than other kinds of air pollutants, either due to the size of the particulate or its chemical composition. Other studies have found a relationship between exposure to wildfire and general respiratory hospital admissions, increases in asthma symptoms, and COPD exacerbations [6 7]. This is the first study, however, to examine the relationship between wildfire-generated air pollution and cystic fibrosis disease activity. Given the mucociliary dysfunction and inflammatory response characteristic of individuals with cystic fibrosis [8], in this population a relationship between wildfire smoke and pulmonary exacerbation is biologically plausible. The intention of this study was to learn more about the relationship between wildfire smoke exposure and pulmonary exacerbation in individuals with cystic fibrosis.

\section{Methods}

\section{Study design}

We implemented a longitudinal design, gathering retrospective data about the cohort for an eight-year period between 2012 and 2019 (inclusive). We utilized data from patients treated at Oregon Health \& Science University's Cystic Fibrosis Care Center (for adults) and Doernbecher Children's Hospital (for children). The Cystic Fibrosis Foundation Patient Registry (CFFPR) database was used to identify individuals seen at these centers during the target period. Individuals were eligible for the study if their record was present in the CFFPR at any time between 2012 and 2019, and if they had also provided a valid zip code to the registry. All patients with CF seen at both centers consented to be included in the CF Foundation's Patient Registry. The primary end point was the number and frequency of severe pulmonary exacerbation (PEx). "Severe pulmonary exacerbation" was defined as a clinical event with respiratory symptoms requiring medical intervention (home IV antibiotics or hospitalization). Episodes occurring within two weeks of a previous exacerbation were assumed to be the same episode of care.

\section{Exposure}

Daily fine particulate matter $\left(\mathrm{PM}_{2.5}\right)$ measurements for the period between 2012 to 2019 were obtained from the EPA's Air Quality System DataMart, a publicly available database. Exposure was determined by linking confirmed patient addresses to the EPA's air quality data; based on their residential zip code, individuals were assigned exposure data from the air quality monitor located nearest their home. In order to identify exposures, daily air quality in an individual's residential zip code was categorized as either "Acceptable" or "Poor." These categories were created using the EPA's Air Quality Index (AQI) definitions, where an AQI over 100 , equivalent to a 24 -hour $\mathrm{PM}_{2.5}$ reading of $35.5 \mu \mathrm{g} / \mathrm{m}^{3}$, is considered "unhealthy for 
sensitive groups" [9]. Individuals residing in areas with a daily Air Quality Index beyond the limit set by the EPA as 'unhealthy for sensitive groups' were considered exposed.

Data was limited to dates occurring during a typical wildfire season in in the Northwestern United States. Although the exact dates of the wildfire season are event-driven and therefore vary from year to year, wildfires in the Northwest occur almost exclusively during the dry summer months, i.e., between June 1st and September 30th. Additionally, because exacerbations secondary to viral infections are more likely during the cold winter months, focusing on summertime exacerbations allowed us to minimize confounding events that may have been triggered by viral illness rather than by smoke exposure.

Air quality monitors measure the amount of particulate in the air, but cannot identify the source of the particulate, or tell whether air pollutants are coming from vehicles, industrial sources, or wildfire. However, because prior research has found that the substantial majority of fine particulate matter air pollution detected in the Pacific Northwest during wildfire season can be attributed to wildfire [10 11], the location of our treatment center allowed us to use summer days with poor air quality as an acceptable surrogate for the presence of wildfire smoke. Liu found that in the western United States $71.3 \%$ of total $\mathrm{PM}_{2.5}$ could be attributed to wildfires on with poor air quality [10]. Other research found that in Pacific Northwest during the 2017 wildfire season - a period of time included in our study - an estimated $85 \%$ of the $\mathrm{PM}_{2.5}$ was due to wildfire [11]. While more efficient vehicles and greater regulations have reduced anthropogenic contributions to air pollution, global warming has caused an increase in the frequency and duration of wildfires. This has meant that a greater proportion of air pollution in the northwestern United States is due to wildfire smoke than to anthropogenic sources such as vehicles and industry [12]. Non-wildfire sources of $\mathrm{PM}_{2.5}$, such as vehicle emissions, are more likely to affect air quality in the winter months, when thermal inversions trap particulate matter close to the ground.

\section{Statistical analysis}

We used patient-days as the increment of analysis, and matched participants to environmental data to see whether the likelihood of experiencing an exacerbation was different for those who had been exposed to wildfire smoke-driven air pollution within the previous 30 days. We queried the CFFPR database to find the residential addresses of study participants, which are confirmed annually. In order to reduce the likelihood of exposure misclassification, we updated the location of participants for every year they participated in the study. The first author created a bespoke $k$ nearest neighbors algorithm with a balltree construction to accurately match patients to the air quality monitor nearest them using zip code [13]. Implausible data for age ( $>70$ years or $<1$ year) and outliers for distance to the nearest air quality monitor (>50 miles) were cleaned from the dataset prior to analysis.

We tabulated the number of wildfire-exposed patient-days and unexposed patient-days and determined whether or not each patient-day contained the start of an exacerbation episode; episodes occurring within 30 days following an exposure were considered exposed exacerbations. Both exacerbations and exposure status were treated as binary variables, and a contingency table was created to determine 
summary statistics [14]. We ran the more conservative Fisher's exact test to confirm that our result would still be statistically significant even if the assumption of normality was incorrect.

A binary logistic regression model of the relationship between exposure and exacerbation was used to compute the univariate odds ratio and its associated confidence interval. Additional variables were added to create a multivariate logistic regression model in order to generate adjusted odds ratios. Age and distance to the nearest air quality monitor were treated as continuous variables; zip code, race, insurance status (a proxy for socio-economic status), month, care center at which the patient was typically seen, and patient state of residence were all considered categorical variables. We conducted sensitivity analyses in order to see which variables influenced the relationship between the exposure and the outcome. Variables were retained in the multivariate model based on significance testing, which was determined with the Wald $z$ value and deviance [15]. Variables that reduced the deviance of the model and had a Wald $\mathrm{z}>=2$ were retained. For adults, only the patient age and yearvariables were significant enough to be retained in the final multivariate model. Patient age, year, and distance to the nearest air quality monitor were significant for pediatric patients.

Variables were also tested for multicollinearity using the variance inflation factor (VIF) set to a threshold of 2.5. The age variable was found to be multicollinear with care center, most likely because the dataset contains information from two hospitals, one which treats adult patients ages 21 and older and one for children under the age of 21. To reduce multicollinearity, patient age was used to stratified the subjects into two categories ( $<21$ years vs. $\geq 21$ years) by care center. All statistical analysis was conducted using Python version 3.7.7.

\section{Results}

\section{Participant Characteristics}

The analysis included 502 people with cystic fibrosis living in the northwestern United States, 82.7\% ( $\mathrm{n}=$ 415) of whom experienced an exposure to wildfire smoke sometime during the study period. One or more exacerbations was experienced by $44.8 \%(n=225)$ of the participants. The mean age of all participants in the study analysis was 18.0 years (SD 14.3), and the average distance to the nearest air quality monitor was 9.1 miles (SD 7.7). More detail about the study population is included in Table 1. Geographically, the participants represented 234 unique zip codes across Oregon and Washington, and the measurements from 56 air quality monitors. The eight-year period of the study generated a total of 427,635 patient-days from 2012 to 2019. 
Table 1

Characteristics of the patient population ${ }^{\text {a }}$

\begin{tabular}{|c|c|c|c|c|}
\hline & & $\begin{array}{l}\text { Overall } \\
(n=502)\end{array}$ & $\begin{array}{l}\text { Ever } \\
\text { exposed } \\
(n=415)\end{array}$ & $\begin{array}{l}\text { Never } \\
\text { exposed } \\
(n=87)\end{array}$ \\
\hline \multirow[t]{2}{*}{$\mathrm{n}(\%)$} & adults ( $>=21$ years) ${ }^{b}$ & 148 & $123(83.1)$ & $25(16.9)$ \\
\hline & children $(<21 \text { years })^{b}$ & 354 & $292(82.5)$ & $62(17.5)$ \\
\hline \multirow[t]{6}{*}{ race, n (\%) } & white & $\begin{array}{l}480 \\
(95.6)\end{array}$ & $399(96.1)$ & $81(93.1)$ \\
\hline & "some other race" & $11(2.2)$ & $9(2.2)$ & $2(2.3)$ \\
\hline & Two or more races & $6(1.2)$ & $4(1.0)$ & $2(2.3)$ \\
\hline & Black & $3(0.6)$ & $2(0.5)$ & $1(1.1)$ \\
\hline & American Indian or Alaska Native & $1(0.2)$ & $1(0.2)$ & 0 \\
\hline & Asian & $1(0.2)$ & 0 & $1(0.2)$ \\
\hline \multirow[t]{3}{*}{ age, mean (SD) } & overall & $\begin{array}{l}18.0 \\
(14.3)\end{array}$ & $18.0(14.2)$ & $17.6(15.1)$ \\
\hline & adults & $\begin{array}{l}31.8 \\
(11.3)\end{array}$ & $31.9(11.0)$ & $31.3(12.6)$ \\
\hline & children & $10.1(6.3)$ & $10.1(6.0)$ & $10.0(7.5)$ \\
\hline \multicolumn{2}{|c|}{$\begin{array}{l}\text { miles from residence to nearest air quality monitor, } \\
\text { mean (SD) }\end{array}$} & $9.1(7.7)$ & $9.2(7.7)$ & $8.6(7.8)$ \\
\hline \multirow[t]{2}{*}{ exacerbation, n (\%) } & yes & 225 & $196(87.1)$ & $29(12.9)$ \\
\hline & no & 277 & $219(79.1)$ & $58(20.9)$ \\
\hline
\end{tabular}

\section{Adult Patients}

For adults with $\mathrm{CF}$, there was a crude odds ratio of $1.57(95 \% \mathrm{Cl}=1.18-2.08, \mathrm{p}=0.002)$ for experiencing a severe pulmonary exacerbation within the month following an exposure to wildfire smoke when compared to the same time period with no wildfire smoke exposure. When controlling for the effects of patient age and the year, the adjusted odds ratio for adults was $1.50(95 \% \mathrm{Cl}=1.12-1.99, \mathrm{p}=0.006)$. Adjusted odds ratios and their associated confidence intervals for all variables in the multivariate model can be found in Table 2 . 
Table 2

Association between outcome and significant variables.

\begin{tabular}{|c|c|c|c|c|c|}
\hline & \multirow{2}{*}{$\begin{array}{l}\text { Variable associated } \\
\text { with exacerbation }\end{array}$} & \multirow{2}{*}{$\begin{array}{l}\text { Adjusted } \\
\text { Odds Ratio }\end{array}$} & \multicolumn{2}{|l|}{$95 \% \mathrm{Cl}$} & \multirow[t]{2}{*}{$p$} \\
\hline & & & $\begin{array}{l}\text { lower } \\
\text { confidence } \\
\text { boundary }\end{array}$ & $\begin{array}{l}\text { upper } \\
\text { confidence } \\
\text { boundary }\end{array}$ & \\
\hline \multirow[t]{3}{*}{$\begin{array}{l}\text { Adults ( } \\
>=21)^{a}\end{array}$} & $\begin{array}{l}\text { Wildfire smoke } \\
\text { exposure }\end{array}$ & 1.496 & 1.125 & 1.991 & 0.006 \\
\hline & age & 0.957 & 0.945 & 0.970 & 0.000 \\
\hline & year & 1.097 & 1.042 & 1.155 & 0.000 \\
\hline \multirow[t]{4}{*}{$\begin{array}{l}\text { Children } \\
(<21)^{a}\end{array}$} & $\begin{array}{l}\text { Wildfire smoke } \\
\text { exposure }\end{array}$ & 0.922 & 0.694 & 1.226 & 0.578 \\
\hline & age & 1.157 & 1.138 & 1.178 & 0.000 \\
\hline & year & 0.946 & 0.912 & 0.981 & 0.003 \\
\hline & distance & 0.976 & 0.976 & 0.999 & 0.035 \\
\hline \multirow[t]{4}{*}{ All } & $\begin{array}{l}\text { Wildfire smoke } \\
\text { exposure }\end{array}$ & 1.113 & 0.911 & 1.361 & 0.295 \\
\hline & age & 1.007 & 1.002 & 1.012 & 0.003 \\
\hline & year & 0.984 & 0.956 & 1.013 & 0.278 \\
\hline & distance & 0.992 & 0.983 & 1.001 & 0.073 \\
\hline
\end{tabular}

Pediatric Patients

For children with $\mathrm{CF}$, there was a crude odds ratio of $0.83(95 \% \mathrm{Cl}=0.63-1.10, \mathrm{p}=0.21)$ for wildfire smoke exposure. The adjusted odds ratio for children, controlling for distance to the nearest air quality monitor, patient age, and year, was $0.92(95 \% \mathrm{Cl}=0.69-1.23, \mathrm{p}=0.58)$.

\section{Discussion}

We found that exposure to wildfire smoke was associated with increased risk for experiencing a pulmonary exacerbation for adults with cystic fibrosis. This suggests that air pollution created by wildfire smoke may be an environmental risk factor for PEx in adult CF patients. To the best of our knowledge this is a novel finding and the first report of this association. Fortunately, precautions can be taken to mitigate exposure to wildfire smoke, and findings such as this allow people with CF and their medical providers to take steps to protect patient health. 
However, our analysis did not show a relationship between wildfire smoke exposure and exacerbation in children with CF. Further study is needed to understand why and how wildfire smoke exposure appears to affect adults with CF differently than the pediatric population.

This research has some limitations. Our study intended only to establish an association, and not causality, between exposure to wildfire smoke and pulmonary exacerbation. Although we controlled for many confounding events, wildfires tend to be more frequent during summers when moisture is low and temperatures are high. It is possible, therefore, that high heat and low humidity are confounders for our study. Further research needs to be done on sensitive populations in order to tease apart the intertwining causal relationships.

Finally, it should be noted that cystic fibrosis is a rare disease, and those who suffer from it are unusually sensitive to pulmonary irritants. However, the frequency and intensity of wildfires is anticipated to grow in the Western United States, as is the population. This means it is likely that growing numbers of people with and without cystic fibrosis will be exposed to wildfire in the coming years, and this sensitive population could potentially be a sentinel warning of the impact of smoke exposure to the general population.

\section{Conclusion}

Ambient wildfire smoke exposure is associated with severe pulmonary exacerbation in adults with cystic fibrosis, suggesting that air pollution created by wildfire smoke may be an environmental risk factor. This association did not hold true for children with CF. Further research is needed to establish causality, understand why and how wildfire smoke exposure affects adult with CF differently than the pediatric population, and determine the clinical applications of this finding.

\section{Declarations}

Funding: Lily A. Cook was supported by Training Grant T15LM007088 from the National Library of Medicine and the National Institute of Environmental Health Science. The content is solely the responsibility of the author and does not necessarily represent the official views of the grantor(s).

Conflicts of interest/competing interests: The authors have no relevant conflicts of interest to declare.

Availability of data and material: Because our dataset includes Protected Health Information, we are unable to make our data available to the public. Inquiries about specific research procedures can be made to the corresponding author.

Code availability: Requests for the code used to analyze the data can be directed to the corresponding author. 
Author contributions: All authors contributed to the study design. Lily A. Cook acquired the environmental and geographic data, performed the data analysis, wrote the article, and revised the final version. Aaron Trimble interfaced with the IRB and the CFFPR, and acquired the patient health data. Bethany Collins contributed to the literature search. All authors provided proofreading, read and approved the final manuscript.

Ethics approval: The protocol for this study was approved by the Institutional Review Board at Oregon Health \& Science University. The study was performed in accordance with the ethical standards as written in the 1964 Declaration of Helsinki and its later amendments or comparable ethical standards.

Consent to participate: All cystic fibrosis patients at Oregon Health \& Science University consented to be included in the CF Foundation's Patient Registry. This study was granted a waiver of informed consent because the study design - a retrospective review of existing records - involved minimal risk. Waiver of the formal written consent process did not adversely affect the rights or welfare of the participants. None of the patients were considered unable to consent on their own behalf.

\section{References}

1. Waters V, Stanojevic S, Atenafu EG, et al (2012) Effect of pulmonary exacerbations on long-term lung function decline in cystic fibrosis. Eur. Respir J 40(1):61-6. doi: 10.1183/09031936.00159111

2. Cystic Fibrosis Foundation (2020) Help Shape CF Research. Available from: https://www.cff.org/GetInvolved/Connect/Help-Shape-CF-Research/. Accessed 10 Nov 2020

3. Farhat SCL, Almeida MB, Silva-Filho L, Farhat J, Rodrigues JC, Braga ALF (2013) Ozone is associated with an increased risk of respiratory exacerbations in patients with cystic fibrosis. Chest 144(4):1186-92. doi: 10.1378/chest.12-2414

4. Goss CH, Newsom SA, Schildcrout JS, Sheppard L, Kaufman JD (2004) Effect of ambient air pollution on pulmonary exacerbations and lung function in cystic fibrosis. Am J Respir Crit Care Med 169(7):816-21. doi: 10.1164/rccm.200306-7790C

5. Goeminne PC, Kicinski M, Vermeulen F, et al (2013) Impact of air pollution on cystic fibrosis pulmonary exacerbations: a case-crossover analysis. Chest 143(4):946-54. doi: 10.1378/chest.121005

6. Liu JC, Wilson A, Mickley LJ, et al (2017) Wildfire-specific fine particulate matter and risk of hospital admissions in urban and rural counties. Epidemiology 28(1):77-85. doi:

10.1097/EDE.0000000000000556

7. Reid CE, Brauer M, Johnston FH, Jerrett M, Balmes JR, Elliott CT (2016) Critical review of health impacts of wildfire smoke exposure. Environ Health Perspect 124(9):1334-43. doi:

10.1289/ehp.1409277

8. Ratjen FA (2009) Cystic fibrosis: Pathogenesis and future treatment strategies. Respir Care 54(5):595 $-605$ 
9. US Environmental Protection Agency (EPA) (2018) Technical assistance document for the reporting of daily air quality - the Air Quality Index (AQI).

10. Liu JC, Mickley LJ, Sulprizio MP, et al (2016) Particulate air pollution from wildfires in the western US under climate change. Clim Change 138(3):655-66. doi: 10.1007/s10584-016-1762-6

11. Zou Y, O'Neill SM, Larkin NK, et al (2019) Machine learning-based integration of high-resolution wildfire smoke simulations and observations for regional health impact assessment. Int $\mathrm{J}$ Environ Res Public Health 16(12). doi: 10.3390/ijerph16122137

12. McClure CD, Jaffe DA (2018) US particulate matter air quality improves except in wildfire-prone areas. Proc Natl Acad Sci 115(31):7901-06. doi: 10.1073/pnas.1804353115

13. Omohundro, SM (1989) Five balltree construction algorithms. Int Comp Sci Inst TR-89-063.

14. Kim HY (2017) Statistical notes for clinical researchers: Risk difference, risk ratio, and odds ratio. Restor Dent Endod 42(1):72-76. doi: 10.5395/rde.2017.42.1.72

15. Vakhitova ZI, Knox CL (2018) Non-significant p-values? Strategies to understand and better determine the importance of effects and interactions in logistic regression. PLoS One 13(11):e0205076. doi: 10.1371/journal.pone.0205076 